\title{
Retrosigmoid Intradural Suprameatal Approach for Petroclival Meningioma
}

\author{
Yukitomo Ishi ${ }^{1,2}$ Shunsuke Terasaka ${ }^{2}$ Hiroaki Motegi ${ }^{2}$ \\ ${ }^{1}$ Department of Neurosurgery, Tomakomai City Hospital, \\ Shimizu-cho, Tomakomai, Japan \\ ${ }^{2}$ Department of Neurosurgery, Hokkaido University School of \\ Medicine, Kita-ku, Sapporo, Japan \\ Address for correspondence Hiroaki Motegi, MD, Department of \\ Neurosurgery, Hokkaido University Graduate School of Medicine, \\ North 15 West 7, Kita-ku, Sapporo 060-8638, Japan \\ (e-mail: moccihiro@gmail.com).
}

J Neurol Surg B 2019;80(suppl S3):S296-S297.

Abstract
Keywords
- petroclival
meningioma
- retrosigmoid
approach
- retrosigmoid
intradural
suprameatal
approach
- suprameatal tubercle
- anterior transpetrosal
approach
- sphenobasal vein
- sylvian vein

Conflict of Interest

None.

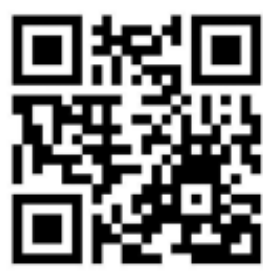

received

May 30, 2018

accepted

August 19, 2018

published online

November 1, 2018
Background Anterior transpetrosal approach and the combined transpetrosal approach are the major surgical approaches for petroclival meningiomas. However, anterior petrosectomy is not preferable in cases with postoperative venous drainage disorder of the sylvian vein due to anatomical variations. Here we present a case of the successful removal of petroclival meningioma by the retrosigmoid intradural suprameatal approach (RISA).

Case Presentation The patient was a 59-year-old woman with incidentally detected right petroclival meningioma. Although she had no neurological deficit, the tumor manifested with gradual growth on annual magnetic resonance imaging (MRI) during an 8-year follow-up. Three-dimensional computed tomography venography (3D-CTV) revealed sphenobasal type of the sylvian vein throughout the lateral side of the foramen ovale. Because the suprameatal tubercle was an obstacle to observe the Meckel's cave, RISA was selected for complete tumor excision. RISA could provide an excellent operative field around the Meckel's cave to confirm the remnant tumor. Postoperative MRI showed no evidence of the tumor, and the patient was discharged without any neurological deficit.

Conclusion RISA can provide a favorable operative field for petroclival meningioma, particularly for cases with high risk of postoperative complications related to the sylvian vein.

The link to the video can be found at: https://youtu.be/cfci_zk0StU. www.thieme.com/skullbasevideos

www.thieme.com/jnlsbvideos
License terms

(c) (i) $\ominus \circledast$
DOI https://doi.org/

10.1055/s-0038-1675168. ISSN 2193-6331. (c) 2019 Georg Thieme Verlag KG Stuttgart · New York \section{.} . 


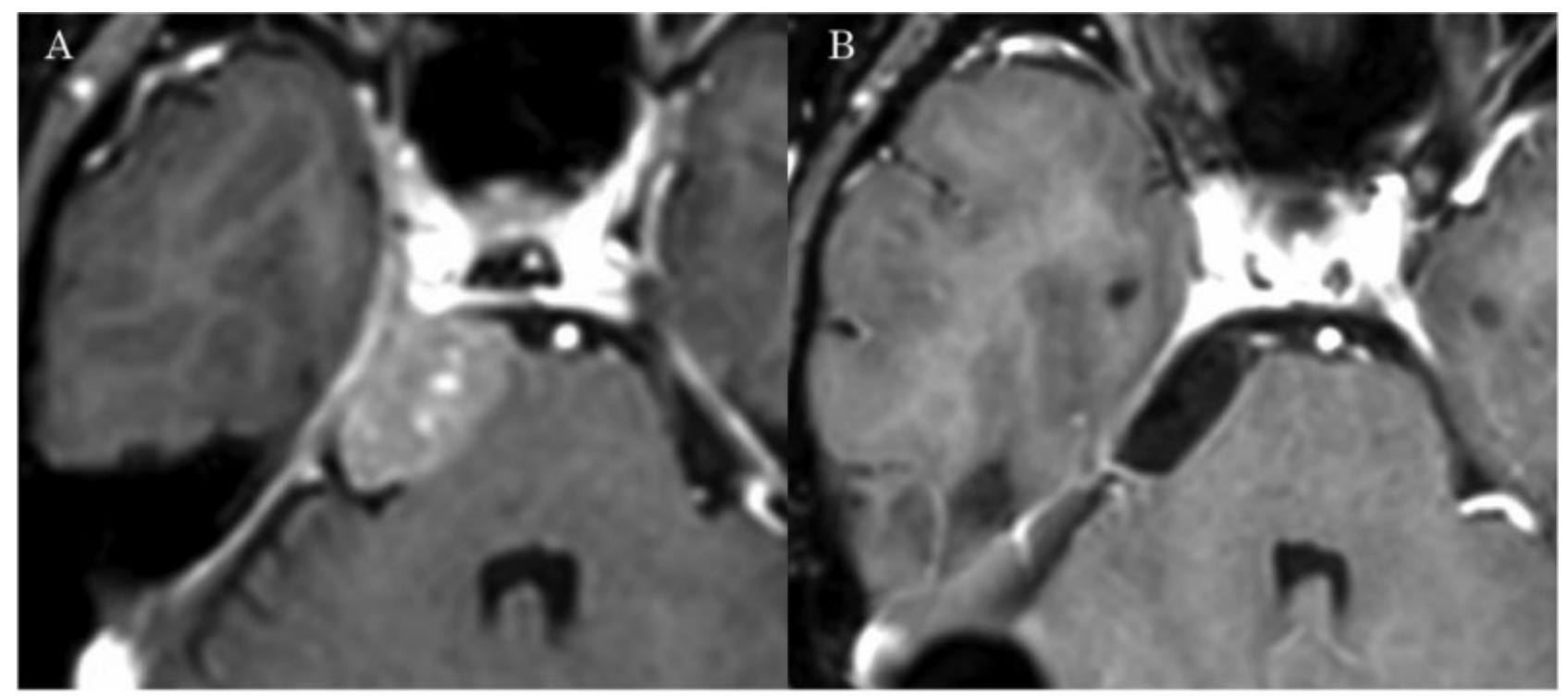

Fig. 1 Pre- and postoperative imaging. (A) Preoperative gadolinium-enhanced T1-weighted imaging (Gd-T1-WI) of magnetic resonance imaging (MRI) presenting with right petroclival meningioma. (B) Postoperative Gd-T1WI of MRI showing no evidence of the tumor.

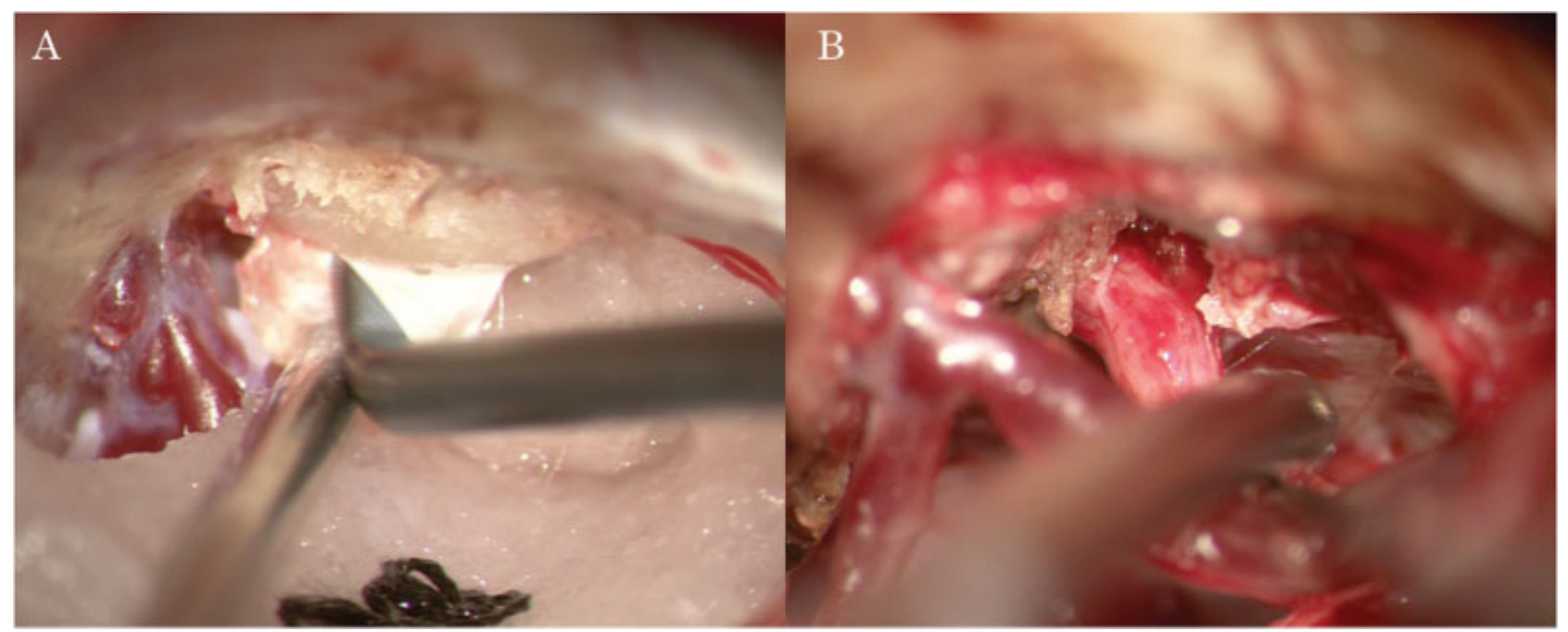

Fig. 2 Intraoperative view. (A) Exposure of the suprameatal tubercle after lateral suboccipital craniotomy. (B) The operative field after tumor removal, presenting a favorable view around the Meckel's cave. 